\title{
Gamma-Irradiation Induces Matrix Metalloproteinase II Expression in a p53-Dependent Manner
}

\author{
Ju-Lin Wang, ${ }^{1}$ Yi Sun, ${ }^{2}$ and Shiyong $\mathrm{Wu}^{1}{ }^{*}$ \\ ${ }^{1}$ Department of Radiation Oncology, Division of Radiation and Cancer Biology, University of Michigan Medical School, \\ Ann Arbor, Michigan \\ ${ }^{2}$ Department of Molecular Biology, Parke-Davis Pharmaceutical Research, Division of Warner-Lambert Company, \\ Ann Arbor, Michigan
}

\begin{abstract}
Matrix metalloproteinases (MMPs) are a family of proteinases that degrade the basement membrane and have been implicated in promoting tumor metastasis. MMP-2, one member of this family, was recently found to be a p53 target and subject to p53 upregulation. In this study, we examined the correlation between the expression of MMP-2 and the increased expression of p53 after $\gamma$-irradiation. Three human p53-positive cell lines that express wild-type p53, including U2-OS (osteosarcoma), RKO (colon carcinoma), MCF-7 (breast carcinoma), one mouse p53 positive cell line and HepG2 (liver carcinoma), and two p53-negative human cell lines, SAOS-2 (osteosarcoma) and RKO-E6 (colon carcinoma), were used in this study. The MMP-2 activity was analyzed by using gelatin zymography. The p53 level was measured by western blot analysis. Our results show that wild-type p53 induced by ionizing radiation caused a subsequent increase of MMP-2 activity in U2-OS and RKO cells but not in MCF-7, HepG2, SAOS-2, or RKO-E6 cells. These results suggest that the $\gamma$-radiation-induced expression of MMP-2 is dependent on the cell type and presence of functional $p 53$. Thus, ionizing radiation could activate MMP-2 activity in a subset of human cancer cells and may lead to an increase in their metastatic potential. Mol. Carcinog. 27:252-258, 2000. ( 2000 Wiley-Liss, Inc.
\end{abstract}

Key words: matrix metalloproteinase II; metastasis; p53; ionization radiation

\section{INTRODUCTION}

The degradation of the basement membrane is catalyzed by a family of matrix metalloproteinases (MMPs) [1]. MMPs play an important role in regulating various physiological processes, such as embryonic development and wound healing, as well as pathological processes such as cancer metastasis and arthritis [2,3]. Studies have shown that the basement membranes of the extracellular matrix are composed mostly of a type IV collagen [4]. The integrity of the basement membrane surrounding a solid tumor is crucial in constraining the invasion and metastasis of the tumor. Invading cancer cells must break down the basement membrane and infiltrate the bloodstream and/or lymphatic system in order to invade distant organs. These invading cancer cells penetrate the basement membrane by secreting proteolytic enzymes that catalyze the degradation of the collagen matrix in the basement membrane [5]. One of the proteolytic enzymes that degrade the basement membrane is the $72-\mathrm{kDa}$ type IV collagenase known as MMP-2 or gelatinase A $[5,6]$. Increased expression of MMP-2 is detected in human colonic adenocarcinoma [7], whereas MMP-2 is knockout mice have reduced angiogenesis and tumor progression capabilities [8]; these experiments support the notion that MMP-2 promotes tumor progression and metastasis. p53 is a tumor suppressor gene as well as a transcriptional factor that controls cell growth by the induction of apoptosis and G1 arrest. This is mainly achieved by p53-induced induction of bax and p21 [9-11]. Intracellular p53 levels can be altered through the exposure of the cells to various insults such as chemical agents [12], ultraviolet radiation [13], and ionizing radiation [14]. We have recently shown that MMP-2 is a p53 target that is subjected to p53 upregulation [15]. Indeed, induction of $p 53$ by the DNA-damaging chemotherapeutic agent etopside increases the level of $M M P-2$ mRNA expression [15]. This study implied that ionizing radiation that activates p53 would increase MMP-2 activity in a subset of human cell lines and may lead to increases in their metastatic potential [16]. To extend this study, we investigated the correlation between p53 activation and MMP-2 induction in multiple cultured human and mouse

*Correspondence to: Department of Radiation Oncology, Division of Radiation and Cancer Biology, University of Michigan Medical School, Ann Arbor, MI 48109.

Received 22 July 1999; Revised 29 December 1999; Accepted 10 January 2000

Abbreviations: MMP, matrix metalloproteinase; SDS, sodium dodecyl sulfate. 
carcinoma cell lines harboring functional p53 or inactive p53. We chose $\gamma$-radiation as a p53 activator, since radiation is such a widely used treatment modality in cancer therapy. We report here that ionizing radiation induced MMP-2 expression in a p53- and cell line-dependent manner.

\section{MATERIALS AND METHODS}

\section{Cell Culture and $\gamma$-Irradiation}

U2-OS and SAOS-2 cells were cultured in McCoy's $5 \mathrm{~A}$ medium containing $10 \%$ fetal calf serum (FCS), L-glutamine, and antibiotics. The RKO and RKO-E6 cells were obtained from Dr. Theodore Lawrence's $\mathrm{lab}$ and were cultured in RPMI 1640 containing $10 \%$ FCS and penicillin/streptomycin $(100 \mathrm{U} / \mathrm{mL})$. MCF-7 cells were cultured in RPMI 1640 containing $10 \%$ FCS and penicillin/streptomycin $(100 \mathrm{U} / \mathrm{mL})$. HepG2 were cultured in Dulbeccos' modified Eagle's medium containing 10\% FCS and penicillin/streptomycin $(100 \mathrm{U} / \mathrm{mL})$. The cells were cultured in $60-$ $\mathrm{mm}$ tissue culture plates in an incubator supplied with $5 \% \mathrm{CO}_{2}$ at $37^{\circ} \mathrm{C}$. The cells were irradiated with an absorbed dose of $5 \mathrm{~Gy}$ by using a ${ }^{60} \mathrm{Co}$ teletherapy unit with a dose rate of $1.49 \mathrm{~Gy} / \mathrm{min}$ (Atomic Energy of Canada, Missisauga, Ontario).

\section{Collection of Condition Media and}

Preparation of Cell Lysates

After the cells were $\gamma$-irradiated, the cell culture media were replaced with fresh serum-free media. The conditioned media from both $\gamma$-irradiated and nonirradiated cells were collected at $0,4,8,12$, and $24 \mathrm{~h}$ postirradiation. In parallel, the cell lysates were prepared by using Tris-glycine sample buffer $[0.2 \mathrm{M}$ Tris- $\mathrm{HCl}, \mathrm{pH} 6.8,5 \%$ (v/v) glycerol, $0.1 \%$ bromophenol blue, and 5\% sodium dodecyl sulfate (SDS)]. Cells from each six-well plate were lysed in $200 \mu \mathrm{L}$ of the Tris-glycine sample buffer. The cell lysates were subsequently sonicated by using a sonicator dismembranator (Fisher Scientific, Pittsburgh, PA), aliquoted, and stored at $-20^{\circ} \mathrm{C}$.

\section{Western Blot Analysis}

The proteins in the cell lysates were resolved on a $10 \%$ SDS-polyacrylamide gel and electrophorized for $50 \mathrm{~min}$ at $200 \mathrm{~V}$. The proteins were then transferred to nitrocellulose membranes (BioTrace HP, Gelman Sciences, Ann Arbor, MI) at $4^{\circ} \mathrm{C}(65 \mathrm{~V}$, $3 \mathrm{~h})$. The membranes were incubated with a p53-Ab2 mouse monoclonal antibody (Calbiochem, La Jolla, CA) at a 1:2000 dilution in TBST $(0.1 \mathrm{M}$ Tris- $\mathrm{HCl}, \mathrm{pH} 6.8,137 \mathrm{mM} \mathrm{NaCl}$, and $0.1 \%$ Tween 20) with $1 \%$ gelatin. The membranes were then probed with an anti-mouse horseradish peroxidaseconjugated secondary antibody and visualized by using a supersignal chemiluminescent kit according to the manufacture's procedure (Pierce, Rockford, IL). Protein loading was standardized through a western blot by using mouse anti-human $\beta$-actin monoclonal antibodies (Sigma, St. Louis, MO) at a 1:10000 dilution. Following the same procedure, the expression levels of p21 and bax were probed with a mouse anti-p21/WAF antibody (Santa Cruz Biotech., Santa Cruz, CA) and a rabbit anti-bax antibody (Santa Cruz Biotechnology, Santa Cruz, CA).

\section{Gelatin Zymography}

MMP-2 levels were measured by using gelatin zymography. A $10 \%$ SDS-polyacrylamide gel was cast in the presence of $0.1 \%$ gelatin. The conditioned medium was mixed with an equal volume of the $2 \times$ Tris-glycine sample buffer described above. The samples were loaded and electrophorized at 125 $\mathrm{V}$ for $90 \mathrm{~min}$. After the electrophoresis, the gel was incubated in a renaturing buffer $(2.5 \%$ Triton $\mathrm{X}-100$ ) for $30 \mathrm{~min}$ at room temperature and then incubated for an additional $30 \mathrm{~min}$ at room temperature in developing buffer $(5 \mathrm{mM}$ Tris, $20 \mathrm{mM} \mathrm{NaCl}, 0.5 \mathrm{mM} \mathrm{CaCl}_{2}$, and $0.02 \%$ Brij 35, pH 7.6). The gels were then incubated in fresh developing buffer for $18 \mathrm{~h}$ at $37^{\circ} \mathrm{C}$. The gels were stained (with 0.5\% Coomassie Blue, $40 \% \mathrm{MeOH}$, and 10\% acetic acid), destained $(40 \% \mathrm{MeOH}, 10 \%$ acetic acid). The intensities of the MMP-2 bands were quantified by using NIH image (Version 1.65).

\section{RESULTS}

Expression of MMP-2 Induced by $\gamma$-Irradiation in U2-OS and RKO Cells but Not in MCF-7 and HepG2 Cells

We have previously shown that p53 positively regulates the expression of MMP-2 [15]. Since $\gamma$-irradiation induces p53 expression [17], we examined whether $\gamma$-irradiation could also induce the expression of MMP-2 in cell lines that express wildtype p53. Three human cancer cell lines and one mouse cancer cell line (U2-OS, RKO, MCF-7, and HepG2) were used in the experiments. The cells were $\gamma$-irradiated with 5 Gy (at $1.49 \mathrm{~Gy} / \mathrm{min}$ absorbed dose rate). At the time indicated in the figures (Figure 1A), the conditioned media were collected from irradiated and nonirradiated cells. The MMP-2 activity in the conditioned media were analyzed by using a gelatin zymography assay. The results show that there were increased levels of MMP-2 in irradiated U2-OS and RKO cell lines as compared with their nonirradiated equivalents (Figure 1A and $\mathrm{B}$ ). The quantitative data suggest that MMP-2 activity began to increase approximately $4-8 \mathrm{~h}$ postirradiation and peaked at $12-24 \mathrm{~h}$ (Figure 2A and B). A $40 \%$ increase of MMP-2 was observed at $24 \mathrm{~h}$ postirradiation for U2-OS cells (Figure 1A) and a 25\% increase was observed for RKO cells (Figure 1B) as compared with their nonirradiated controls. In contrast to U2-OS and RKO cells, the MMP-2 activity was not changed after 


\section{A $\quad \underline{\text { U2-OS Cells }}$}

\section{$0 \mathrm{~Gy}$}

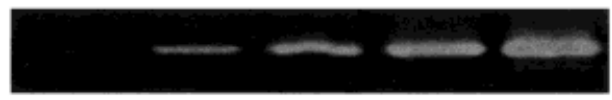

5 Gy

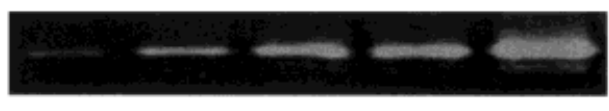

Time (h)

4

8

12

24

Figure 1. Conditioned media from U2-OS and RKO cells show an increased activity of MMP-2 in the irradiated fractions. U2-OS cells were cultured in McCoy's $5 \mathrm{~A}$ medium containing $10 \% \mathrm{FCS}$, and the RKO cells were cultured in RPMI 1640 containing $10 \%$ FCS. One day before irradiation, the cells were seeded into $60-\mathrm{mm}$ tissue culture plates at $50 \%$ confluency. The cells were irradiated with an absorbed
B $\quad \underline{\text { RKO Cells }}$

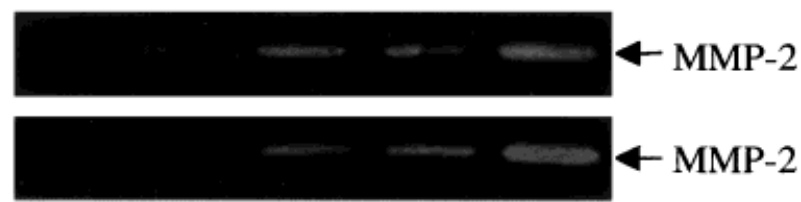

0

4

8

12

24

dose of $5 \mathrm{~Gy}$. The conditioned media from the irradiated and nonirradiated U2-OS (A) or irradiated and nonirradiated RKO cells (B) were collected at various timepoints as indicated. Zymography was performed on the media to determine the MMP-2 activity present. The levels of MMP-2 were quantitated by using $\mathrm{NIH}$ image (version 1.61).
A:

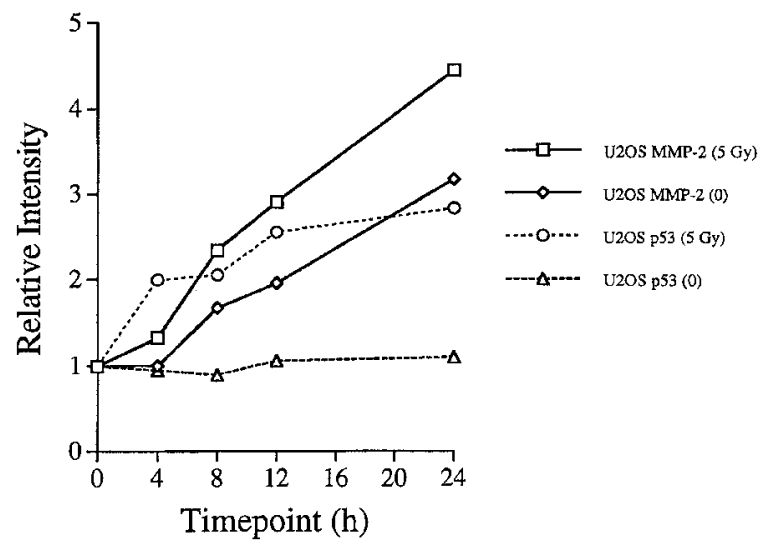

B:

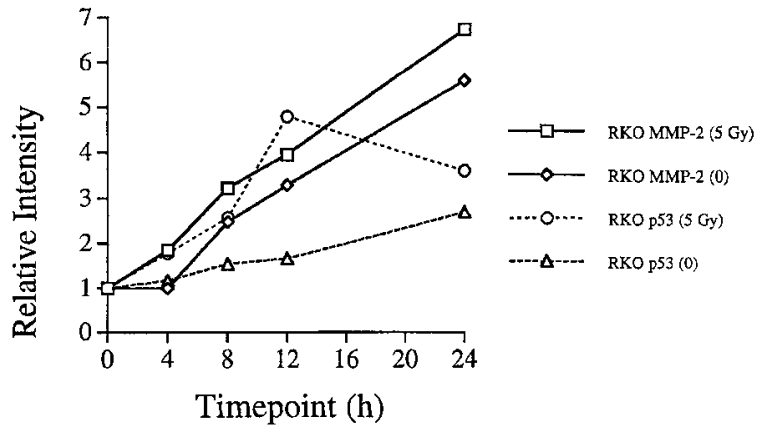

Figure 2. Normalized graphs of U2-OS and RKO cell lines indicating an increase in MMP- 2 and p53 levels after $\gamma$-irradiation. These graphs depict the levels of MMP-2 in media over a course of time compared with the levels of p53 for U2-OS (A) and RKO cells (A) The MMP-2 and $p 53$ levels were normalized with respect to control time points taken at the zero-hour time point. The graphs also indicate the net difference between the irradiated and nonirradiated control cell extracts and conditioned media that were collected synchronously during the specified timepoint. The resultant intensity quantification
$\mathrm{C}:$

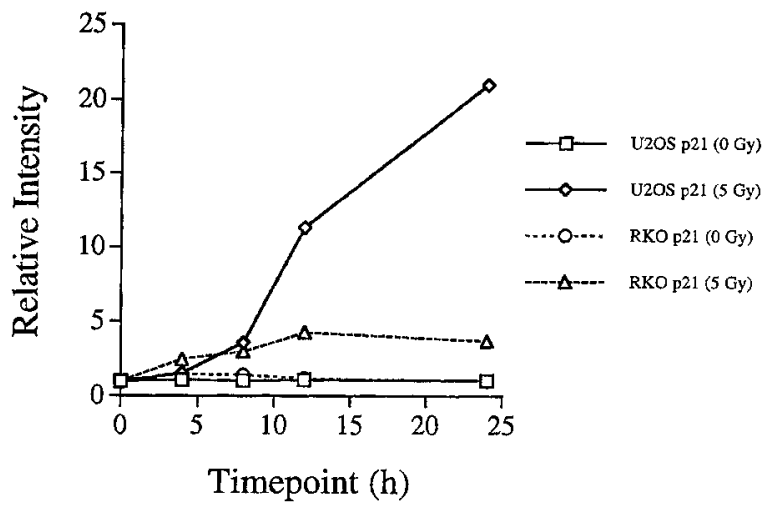

D:

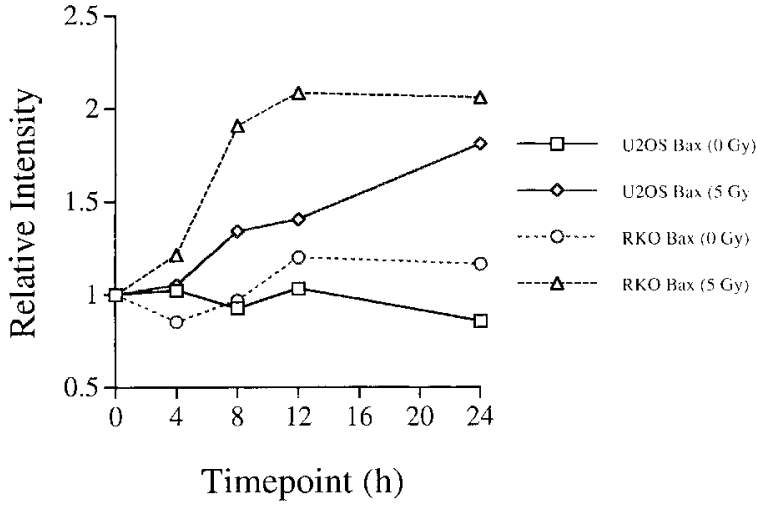

for the nonirradiated fractions was subtracted from the intensity quantification fractions, for the irradiated fraction, giving rise to the net increase of p53 and MMP-2 levels seen on the graphs. The numbers are the average of three to five sets of data. The calculated errors for the MMP- 2 graphs ranged from \pm 0.06 to \pm 0.43 . The calculated errors for the $\mathrm{p} 53$ graphs in ranged \pm 0.07 to \pm 0.32 . The western blots for p21 and bax were also quantified and graphed (B and $C$ ). The calculated errors for the $\mathrm{p} 21$ and bax graphs range from \pm 0.11 to \pm 0.85 and \pm 0.08 to \pm 0.26 , respectively. 
irradiation in the conditioned media from MCF-7 and HepG2 cells, even though the p53 levels in these cell lines increased after $\gamma$-irradiation (data not shown). The results suggest that MMP-2 expression can be increased by $\gamma$-irradiation in certain types of cell lines.

\section{Radiation-Induced Expression of MMP-2 Correlated} with the Increased Expression of p53

It has been well documented that exposure of cells to varying doses of $\gamma$-radiation can increase the activity of the p53 protein [17]. Further studies have shown that wild-type p53 plays a role in the regulation of metastatic factors such as MMP-2 [15]. The U2-OS (human osteosarcoma) and RKO (human colon carcinoma) tumor cell lines used in this study both express wild-type p53. The same dosage (5 Gy) of ionizing radiation that induced MMP-2 expression was used to treat the cells. The p53 expression in the $\gamma$-irradiated and nonirradiated cells was determined by using western blot analysis.

$\underline{\mathrm{U} 2-\mathrm{OS}}$

A

0 Gy 5 Gy

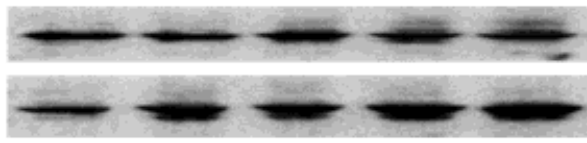

Time (h)

0

4

8

12

24

B

0 Gy

5 Gy

Time (h)

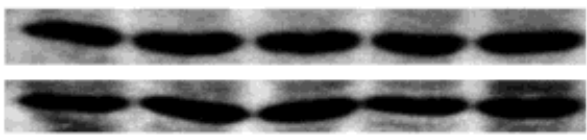

0

4

8

12

24

C

0 Gy

5 Gy

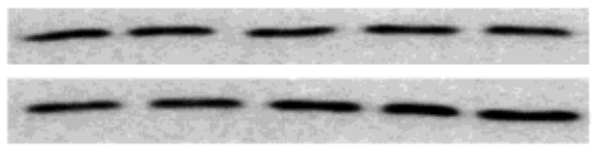

Time (h)

0

4

8

12

24

D

\section{$0 \mathrm{~Gy}$ \\ 5 Gy}

Time (h)

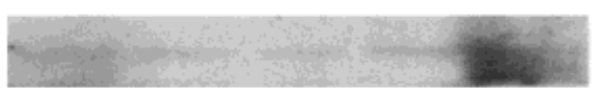

Figure 3. Intracellular p53 levels increased in response to ionizing radiation. The cell lysates were prepared as described in the Materials and Methods. Equal volumes $(8 \mu \mathrm{L})$ of lysates were resolved on a $10 \%$ SDS-polyacrylamide gel and transferred to nitrocellulose membranes. The membranes were incubated accordingly with a first antibody, then probed with a horseradish peroxidase-conjugated secondary antibody and visualized by using a chemiluminescent kit according to the manufacture's procedure (Pierce, Rockford, IL). (A) p53 expression in irradiated and nonirradiated U2-OS and RKO cells. A mouse anti-p53 monoclonal antibody (Ab-2, Calbio-
As shown (Figure $2 \mathrm{~A}$ and $\mathrm{B}$ ), this dose of irradiation also increased p53 expression in those cell lines over a 24-h time course as compared with nonirradiated controls. The protein amount loaded on the gel was monitored and normalized with a $\beta$-actin antibody, a housekeeping protein (Figure 3B). As shown (Figure 3A and $\mathrm{B}$ ), the level of p53 protein increased at $4-8 \mathrm{~h}$ postirradiation and peak levels were reached at $12-24 \mathrm{~h}$ after the initial exposure to ionizing radiation. These results indicate that ionizing radiation can increase the expression of p53, which correlates with the activation of MMP2.

In order to confirm that the expressed p53 is active, we examined the expression of $\mathrm{p} 21$ and bax upon $\gamma$-irradiation. Previous data have shown that activated p53 can induce the increased production of p21 [18] and bax [19]. The blots were performed on the p53-expressing U2-OS and RKO cell lines as well as the p53-negative SAOS and RKO-E6 celllines. Our results indicate that in the p53-positive

\section{$\underline{\mathrm{RKO}}$}
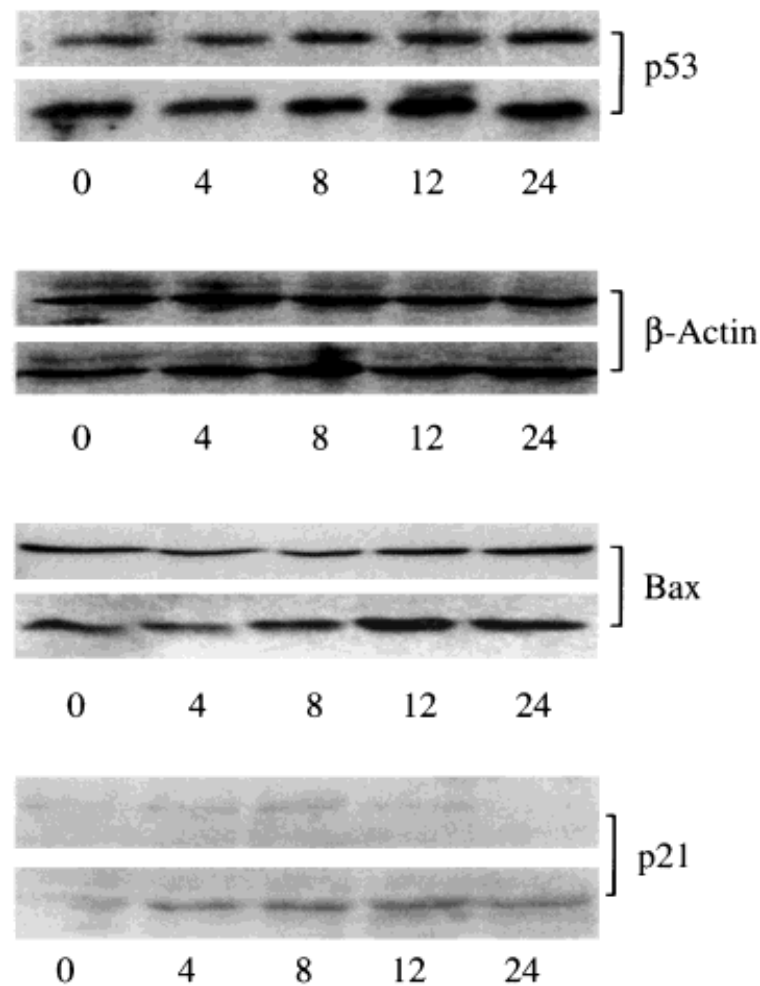

chem, La Jolla CA) was used to detect the level of p53. (B) $\beta$-actin expression in irradiated and nonirradiated U2-OS and RKO cells. The membrane was incubated with a mouse anti- $\beta$-actin polyclonal antibody (Sigma, St. Louis). (C) bax expression in irradiated and nonirradiated U2-OS and RKO cells. A rabbit anti-bax antibody (Santa Cruz Biotechnology, Santa Cruz, CA) was used in this experiment. (D) p21 expression in irradiated and nonirradiated U2OS and RKO cells. The blots were performed by using $(\alpha)$ anti21MAF antibody (Santa Cruz Biotechnology). 
cell lines, the cells that were irradiated showed increased levels of p21 and bax, while the cells that were not irradiated had constant levels of p21 and bax (Figure 3C and D) with quantitation, (Fig. 2C and D). The increased expressions of p21 and bax are in accordance with the increase of p53 in the cells (Figure 3A) indicating that the increased p53 level correlates to the increased activity of p53. The p53-negative cell lines (SAOS-2 and RKO-E6) expressed very low levels of p21 or bax, and $\gamma$ irradiation has no effect on their expression (data not shown).

\section{MMP-2 Secretion Dependent on Functional p53}

To determine whether wild-type p53 is necessary for the expression of MMP-2, we examined MMP-2 expression in two p53-negative cell lines. In the first cell line were SAOS- 2 cells, which had the $p 53$ gene deleted [20]. Previous studies indicate that SAOS-2 cells are devoid of p53 [21]. The second cell line was the RKO-E6 cells, which are derived from RKO cells infected with a human papillomavirus E6 gene that results in the degradation of p53 through an ubiquitin-mediated pathway [22]. Using these two cell lines, we analyzed the activity by zymography and the expression of MMP-2 by western bloting in both the irradiated and nonirradiated cells. Interestingly, the MMP-2 activities in the conditioned media from these two cell lines were undetectable (Figure 4, lanes 2 and 4). The MMP-2 activity in conditioned media after irradiation was also undetectable (data not shown). However, MMP-2 protein was expressed in both SAOS-2 and RKO-E6 cells (Figure 5, lanes 2 and 4). Interestingly, the ratio of pre-MMP-2 to MMP-2 is much higher in SAOS-2 and RKO-E6 cells than in U2-OS cells (Figure 5, lanes 2 vs 1 ) and RKO cells (Figure 5, lane 4 vs 3 ). The preMMP-2 level was 43\% in U2-OS cells, $64 \%$ in SAOS-2 cells, $65 \%$ in RKO cells, and 79\% in RKO-E6 cells. Our results suggest that p53 may not only be involved in radiation-induced expression of MMP-2 but may also be involved in MMP-2 processing, activation, and secretion.

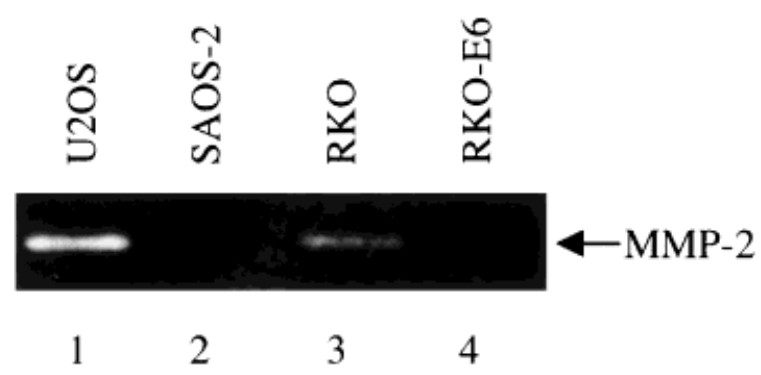

Figure 4. MMP-2 secretion dependent on p53. Zymography of conditioned media taken from the 24-h time points in four different cell lines (U2-OS, RKO, SAOS, and RKO-E6) indicated the presence of MMP-2 activity in the p53-positive cell lines (lanes 1 and 3 ) but little or no MMP-2 activity in the p53-negative cell lines (lanes 2 and 4).

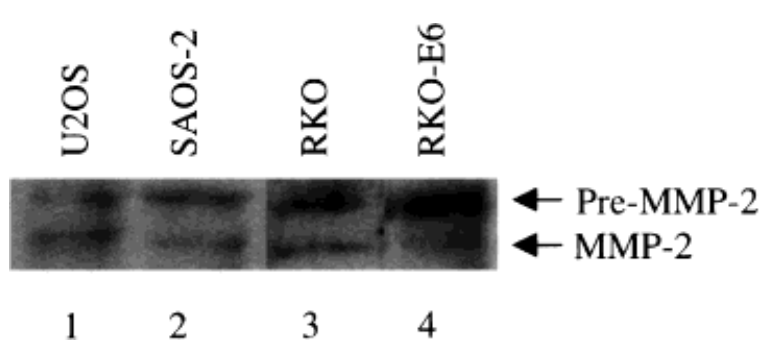

Figure 5. Higher pre-MMP-2 level in p53-negative cells. The cell lysates were prepared as described in the Materials and Methods. Equal volume $(8 \mu \mathrm{L})$ of lysates was resolved on a $10 \%$ SDS-polyacrylamide gel and transferred to a nitrocellulose membrane. The level of MMP-2 was determined by western blot analysis by using an MMP-2 Ab-3 antibody (Calbiochem, La Jolla CA). The data indicate that there was a higher percentage of pre-MMP-2 in p53-negative cells (lanes 2 and 4) than in p53-positive cells (lanes 1 and 3).

\section{DISCUSSION}

Tumor metastasis is a complex process and can be largely divided into three phases: (i) escape of the tumor cells from the mass of primary tumor and dissemination of the cells through the lymphatics or blood vessels, (ii) penetration through vessel walls and other tissue barriers, and (iii) growth at the new site [2]. Many genes have been implicated in this process. Some of the metastasis-associated genes are regulated either positively or negatively by p53. Examples include $M M P-1, M M P-2$, epidermal growth factor receptor, cathepsin $D$, basic fibroblast growth factor, MDR1, thrombospondin-1, and KAI-1 $[16,23]$. Since radiation has been shown to induce p53, it has been hypothesized that radiotherapy may promote tumor metastasis in a subset of human cancers harboring wild-type p53 [16]. It has also been found that increased expression of p53 affects the metastatic potential of certain types of cancers [24].

Using three human cancer cell lines and one mouse cancer cell line that harbor wild-type p53, as well as two p53-negative cell lines, we showed that the MMP-2 activities in conditioned media harvested from U2-OS and RKO cells were induced by $\gamma$ irradiation. Interestingly, the MMP-2 activities did not change in conditioned media harvested from irradiated HepG2 and MCF-7 cells even though they showed a significant increase in p53 levels after radiation treatment (data not shown). Thus, it appears that MMP-2 activity can only be induced by $\gamma$-irradiation in certain types of cells. These results may explain the previous observations that radiation therapy can increase hematogenous metastasis in some tumors but not in others [25]. We have also shown that the radiation-induced expression of MMP-2 correlated with the expression level of p53. In U2-OS cells, p53 was induced within $4 \mathrm{~h}$, and MMP-2 activity was increased from 4 to $24 \mathrm{~h}$. Likewise, in RKO cells, p53 was induced at $12 \mathrm{~h}$, postirradiation, and MMP- 2 activity reached its peak at $24 \mathrm{~h}$. These results further suggest that MMP-2 increase is a consequence of increased levels of wild- 
type p53 induced by exposure to $\gamma$-radiation. It is, however, not clear why p53-mediated MMP-2 activation by irradiation is cell-line dependent.

To further confirm that the increased expression of MMP-2 is p53 dependent, we examined the MMP2 expression after $\gamma$-irradiation in p53-negative cell lines. Two p53-negative human cancer cell lines, SAOS-2 (human osteosarcoma) and RKO-E6 (human colon cancer), were also used in the study. Indeed, MMP-2 expression was not induced in these two cell lines, indicating that MMP- 2 induction by $\gamma$-irradiation is p53-dependent. We also measured the amounts of p21 and bax in the cell lysates. This was done because p21 and bax protein levels correlated with the level of p53 being expressed. Our data suggest that the levels of p21 and bax increase as the levels of p53 increase in response to radiation in U2-OS and RKO cells. The expression levels of p21 and bax did not increase in SAOS-2 and RKO-E6 cells (data not shown), which indicates that the $\gamma$-irradiation-induced p21 and bax expressions are p53-dependent. In addition, it was interesting to find that the expressed MMP-2 was not efficiently secreted into the conditioned media by these two cell lines. Our data suggest that the pre-MMP-2 is not efficiently matured in SAOS-2 and RKO-E6 cells. These results suggest that p53 may even play a role in the maturation of MMP-2.

In conclusion, we have shown that wild-type p53 activated by $\gamma$-irradiation induces an increased level of MMP-2 expression. The p53 "status" of a certain cancer appears to play a role in the determination of whether MMP-2 is activated by DNA damage. Thus, it is possible that a subset of human cancer with wild-type p53 may undergo metastasis upon radiotherapy via MMP-2 activation. If this is the case, the next challenge will be how to determine the metastatic potential of a patient's tumor when exposed to radiation. This will require an in-depth understanding of in vivo regulation of MMP-2 and other metastasic genes [16] and the tumor context. Nevertheless, the finding reported here serves as the first step in understanding regulation of MMP-2 expression by radiation in the context of p53 status. MMP-2 status of cancer cells can be potentially used as a prognostic factor for predicting the outcome of certain forms of bladder cancer [26]. Thus, a better understanding of the activation of MMP-2 and p53 by various factors will not only lead to an improved disease prognosis but also aid in the development of treatment strategies that are more safe and effective.

\section{ACKNOWLEDGMENTS}

We are grateful to Dr. Theodore Lawrence, Dr. Mary Davis, and Dr. Mats Ljungman for providing cell lines, reagents, and support. We are also greatly indebted to Amy Pace for her expertise in editing the figures in this publication. Finally, we would also like to thank Dr. Alnawaz Rehemtulla and Dr. Daniel Hamstra for their insightful discussions and suggestions.

\section{REFERENCES}

1. Giambernardi TA, Grant GM, Taylor GP, et al. Overview of matrix metalloproteinase expression in cultured human cells. Matrix Biol 1998;16:483-496.

2. Liotta LA, Stetler-Stevenson WG. Metalloproteinases and cancer invasion. Semin Cancer Biol 1990;1:99-106.

3. Stetler-Stevenson WG, Aznavoorian S, Liotta LA. Tumor cell interactions with the extracellular matrix during invasion and metastasis. Annu Rev Cell Biol 1993:9:541-573.

4. Deryugina El, Luo GX, Reisfeld RA, Bourdon MA, Strongin A. Tumor cell invasion through matrigel is regulated by activated matrix metalloproteinase-2. Anticancer Res 1997; 17:3201-3210.

5. Cao J, Rehemtulla A, Bahou W, Zucker S. Membrane type matrix metalloproteinase 1 activates pro-gelatinase $A$ without furin cleavage of the N-terminal domain. J Biol Chem 1996;271:30174-30180

6. MacDougall JR, Matrisian LM. Contributions of tumor and stromal matrix metalloproteinases to tumor progression, invasion and metastasis. Cancer Metastasis Rev 1995;14: 351-362.

7. Levy AT, Cioce V, Sobel ME, et al. Increased expression of the $M_{r} 72,000$ type IV collagenase in human colonic adenocarcinoma. Cancer Res 1991;51:439-444.

8. Itoh T, Tanioka M, Yoshida H, Yoshioka T, Nishimoto $H$, Itohara S. Reduced angiogenesis and tumor progression in gelatinase A-deficient mice. Cancer Res 1998:58: 1048-1051.

9. el-Deiry WS, Tokino T, Velculescu VE, et al. WAF1, a potential mediator of $p 53$ tumor suppression. Cell 1993;75: 817-825.

10. Miyashita T, Reed JC. Tumor suppressor p53 is a direct transcriptional activator of the human bax gene. Cell 1995; 80:293-299.

11. Ko LJ, Prives C. p53: Puzzle and paradigm. Genes Dev 1996;10:1054-1072.

12. Sun $Y$, Bian J, Wang $Y$, Jacobs C. Activation of $p 53$ transcriptional activity by 1,10-phenanthroline, a metal chelator and redox sensitive compound. Oncogene 1997; 14:385-393.

13. Li G, Ho VC. p53-dependent DNA repair and apoptosis respond differently to high- and low-dose ultraviolet radiation. Br J Dermatol 1998;139:3-10.

14. Chang D, Chen F, Zhang F, McKay BC, Ljungman M. Dosedependent effects of DNA-damaging agents on p53mediated cell cycle arrest. Cell Growth Differ 1999;10: 155-162.

15. Bian J, Sun Y. Transcriptional activation by $p 53$ of the human type IV collagenase (gelatinase A or matrix metalloproteinase 2) promoter. Mol Cell Biol 1997;17:6330-6338.

16. Sun $Y$, Wicha M, Leopold WR. Regulation of metastasisrelated gene expression by p53: A potential clinical implication. Mol Carcinog 1999;24:25-28.

17. Ohnishi T, Wang X, Takahashi A, Ohnishi K, Ejima Y. Lowdose-rate radiation attenuates the response of the tumor suppressor TP53. Radiat Res 1999;151:368-372.

18. Thornborrow EC, Manfredi JJ. One mechanism for cell typespecific regulation of the Bax promoter by the tumor suppressor $p 53$ is dictated by the p53 response element. J Biol Chem 1999;274:33747-33756.

19. Ludes-Meyers $J H$, Subler MA, Shivakumar CV, et al. Transcriptional activation of the human epidermal growth factor receptor promoter by human p53. Mol Cell Biol 1996; 16:6009-6019.

20. Masuda H, Miller C, Koeffler HP, Battifora H, Cline MJ. Rearrangement of the p53 gene in human osteogenic sarcomas. Proc Natl Acad Sci USA 1987;84:7716-7719. 
21. Okaichi $K$, Wang LH, Ihara M, Okumura Y. Sensitivity to ionizing radiation in SAOS-2 cells transfected with mutant p53 genes depends on the mutation position. J Radiat Res (Tokyo) 1998;39:111-118.

22. Scheffner $M$, Werness BA, Huibregtse JM, Levine AJ, Howley PM. The E6 oncoprotein encoded by human papilloma virus types 16 and 18 promotes the degradation of p53. Cell 1990;63:1129-1136.

23. Sun $Y$, Wenger $L$, Rutter $J L$, Brinckerhoff $C E$, Cheung $H S$. p53 down-regulates human matrix metalloproteinase-1 (collagenase-1) gene expression. J Biol Chem 1999;274: 11535-11540.
24. Cheng L, Leibovich BC, Bergstralh EJ, et al. p53 alteration in regional lymph node metastases from prostate carcinoma: A marker for progression? Cancer 1999;85: 2455-2459.

25. Nathanson SD, Westrick P, Anaya P, Hetzel FW, Jacobsen G. Relationship of spontaneous regional lymph node metastases to dose of local irradiation of primary B16 melanomas. Cancer Res 1989;49:4412-4416.

26. Kanayama H, Yokota K, Kurokawa Y, Murakami Y, Nishitani M, Kagawa S. Prognostic values of matrix metalloproteinase-2 and tissue inhibitor of metalloproteinase-2 expression in bladder cancer. Cancer 1998;82:1359-1366. 